\title{
O processo de circulação de informações sobre forró eletrônico e seu fluxo comunicacional em Fortaleza $^{1}$
}

\author{
Robson da Silva Braga \\ Doutor; Universidade do Estado do Rio de Janeiro (UERJ), Rio de Janeiro, RJ, Brasil; \\ robsonsilvabraga2@gmail.com \\ Valdir Jose Morigi \\ Doutor; Universidade Federal do Rio Grande do Sul (UFRGS), Porto Alegre, RS, Brasil; \\ valdir.morigi@gmail.com
}

Resumo: Com base em entrevistas com produtores e consumidores de forró eletrônico, este artigo reflete sobre o processo de circulação desse gênero musical em Fortaleza, capital do Ceará, aportando-se nos conceitos de "fluxo comunicacional" e "sistema de resposta social", de José Luiz Braga (2006). Esse produto cultural não é resultado exclusivo do trabalho de uma indústria fonográfica, mas de um processo sociocultural mais amplo, que, em um fluxo comunicacional, dá base cultural à produção, interfere no modo como esse produto circula pela cidade e, mais que isso, atribui novos sentidos a esse produto através de um "sistema de resposta social".

Palavras-chave: Forró Eletrônico. Circulação da Informação. Midiatização.

\section{Introdução}

Este artigo reflete sobre o processo de circulação do forró eletrônico em Fortaleza, aportando-se nos conceitos de "fluxo comunicacional" e "sistema de resposta social”, de José Luiz Braga (2006).

Algumas das interpretações mais recorrentes acerca da "indústria do forró eletrônico"2 - cujas empresas se destacam no mercado musical de Fortaleza, capital do Ceará, desde a década de 1990 - apontam para a existência de um conjunto de produtores culturais responsáveis por impor e difundir uma música que "nada tem a ver com a cultura regional". ${ }^{3}$ Tais interpretações, simplistas e reducionistas ao extremo, subestimam o poder que a cultura exerce sobre a co- 
municação e - por que não? - o poder que a comunicação exerce sobre a cultura (MARTÍN-BARBERO, 2009). ${ }^{4}$

O forró eletrônico seria, na interpretação que propomos aqui, um produto não somente industrial, mas cultural. Trata-se de um produto forjado por um contexto sociocultural com suas singularidades e, por isso, não é gerado exclusivamente por uma indústria, e seus sentidos não são dados de modo acabado a um grupo de consumidores. Ao contrário, é resultado da circulação de informações que se inserem em um complexo fluxo de comunicação; assim, apenas aparentemente é criado e finalizado no âmbito da indústria fonográfica.

Para produzir suas canções, tal indústria se ancora em elementos culturais que estão diluídos na sociedade, o que nos permite considerar que essa “produção" não se inicia em um único "produtor”, e sim, segue um fluxo comunicacional. Além disso, o produto não sai da "linha de produção" com seus "significados únicos e encerrados em si”. Ao ser consumido pela sociedade, os sujeitos o fazem circular e, nesse processo de circulação, atribuem novos sentidos ao produto.

Partindo desses pressupostos, analisamos de que modo o processo de circulação das informações sobre o "forró eletrônico" em Fortaleza alimenta o fluxo comunicacional a que esse produto cultural está submetido. A análise tem por base empírica entrevistas ${ }^{5}$ realizadas em 2011 e 2012 com produtores e consumidores do forró eletrônico na capital cearense, além de observação participante em clubes de forró e emissoras de rádio e televisão da cidade.

\section{Midiatização da Informação como Base Epistemológica}

Para fundamentar a interpretação proposta acima, partimos da discussão sobre a circulação da informação midiática, tendo por base as reflexões propostas por pesquisadores como José Luiz Braga (2006) e Antônio Fausto Neto (2006; 2008; 2010). Ambos têm por base epistemológica as discussões sobre midiatização.

Gomes (2008) considera que o método de cada ciência deve ser determinado pelo seu objeto. Para pensar sobre tais métodos, o autor parte de uma com- 
preensão complexa acerca do objeto da comunicação, ao considerá-lo como um fenômeno que não se encerra em si mesmo, e sim "como auto-manifestação do ser", como "agente da realização do conjunto de relações constitutivas do 'nós' da sociedade" (2008, p. 8).

Os estudos de comunicação devem, portanto, considerar os "meios de comunicação social" não como um conjunto de empresas de comunicação, mas como um sistema social de comunicação, que envolve diversos agentes sociais que interferem no processo midiático em diversos níveis. "Eles [processos midiáticos] devem ser tomados na sua totalidade, com suas relações, conexões e interconexões e não podem mais ser fragmentados em suas partes: produtor, produção, conteúdo, veículo, público, receptor, recepção" (GOMES, 2008, p. 16).

A análise, portanto, recai sobre os processos de midiatização a partir de uma abordagem ampla, que vai além das práticas midiáticas, buscando compreender como a sociedade se relaciona com os dispositivos tecnológicos de comunicação. Através do conceito de midiatização, buscamos compreender tais processos midiáticos a partir de categorias como a circulação, recepção, mediação das informações que alimentam os fluxos comunicativos e interações entre campos sociais.

Tal perspectiva parte da compreensão de que passamos de uma "sociedade dos meios" para uma "sociedade em midiatização". Na "sociedade dos meios", as mídias convencionais (rádio e televisão, principalmente) exerceriam um papel de protagonista, mediando a relação entre a sociedade e campos sociais como a política e a economia. Já na "sociedade em midiatização", os avanços tecnológicos fizeram emergir novos aparatos tecnológicos (o computador e a Internet, por exemplo), novas mídias e, consequentemente, novos feedbacks, novas ambiências. Esse processo se intensifica na medida em que se complexifica a cultura digital, caracterizada por uma cultura da convergência, através da qual tecnologias e protocolos de comunicação promovem novos usos e apropriações midiáticas (JENKINS, 2008).

$\mathrm{Na}$ atual "sociedade em midiatização", o que está em questão não são apenas os novos dispositivos tecnológicos, mas novas ambiências midiáticas que redefinem o tecido social. A atividade midiática expande suas fronteiras, para 
além dos meios convencionais, chegando a diversos outros grupos sociais, que passam a ter acesso a alguns aparatos tecnológicos de comunicação, na chamada “operação em mídia expandida” (FAUSTO NETO, 2006).

O "protocolo da interpretação", que seria mais intenso na sociedade dos meios, entra em declínio e torna-se secundário diante do "protocolo da indicialidade", que marca a sociedade em midiatização. "Passa-se da significação ao ato indicial. A subjetividade não se realiza mais pelos 'pensamentos discretos', mas segundo economias enunciativas ditadas pela lógica dos fluxos. $\mathrm{O}$ ator social - o narrador - se torna em uma nova espécie de intérprete, um operador de indicialidades, de conexões" (FAUSTO NETO, 2006, p. 5).

$\mathrm{Na}$ transição de uma sociedade à outra, o campo midiático estaria tramando uma rede de informações que permeia os demais campos (como o trabalho, a família, a política, a economia e a religião) e modifica o nosso modo de ser no mundo. O processo de midiatização, portanto, afetaria todos os campos da sociedade, inclusive o midiático.

Apesar das diferenças entre essas duas sociedades ("sociedade dos meios" e "sociedade em midiatização"), as lógicas comunicacionais permanecem como centrais em ambas, responsáveis por redesenhar setores como economia, política e religião. Assim, o aparato tecnológico não se impõe ao tecido social, e sim redesenha esse tecido social ao inserir nele suas lógicas. Os pressupostos e as lógicas da "cultura da mídia" estariam atravessando os diversos campos sociais e interferindo na constituição e no funcionamento da sociedade (FAUSTO NETO, 2008).

O "em" contido na nomenclatura "sociedade em midiatização" dá ideia de "processo" e ajuda a explicar por que a "midiatização é um fenômeno em crescente desenvolvimento". Tal sociedade em midiatização, na qual vivemos atualmente, está em constante transformação, adequando-se não somente aos novos dispositivos midiáticos, mas às novas ordens sociais e às novas lógicas que reestruturam as interações sociais, remodelam os processos de circulação das informações e dos fluxos de comunicação, reordenam as forças da sociedade e seus domínios técnicos e políticos. 
Para Braga (2006, p. 17), a expressão "incompletude" define os “[...] grandes espaços vazios de processualidade, práticas sociais tateantes, conhecimento teórico insuficientemente formulado e - particularmente - uma grande inexperiência sociocultural no uso de tais processos."

A mediatização não pode ser considerada estabelecida no mesmo nível em que a cultura escrita foi referência como processo interacional (e ainda é, parcialmente). No desenvolvimento de suas lógicas interacionais (em processo de instauração), algumas insuficiências vêm sendo 'resolvidas' (em processos que fortalecem estas lógicas). Assim, por exemplo, se o processo é interacional, a ausência de retorno é um 'calcanhar de Aquiles'. Nessa perspectiva, a Internet é um desdobramento socialmente 'lógico' do rádio e da TV a partir das críticas e resistências quanto à 'unidirecionalidade'; assim como a segmentação é uma resposta processual aos limites da 'massificação'. (BRAGA, 2006, p. 17).

Gomes (2010) considera ser mais importante perceber, por exemplo, quais religiões (e aí podemos estender para outros campos, como a política e a economia) estão emergindo a partir dos novos processos midiáticos que temos experimentado. "[...] a pergunta não deve ser o que as religiões fazem com a mídia, mas que religião está emergindo da mídia." (GOMES, 2010, p. 3). Essa passagem exemplifica parte da discussão proposta pela perspectiva teórica da midiatização, afinal os usos das mídias pela sociedade não seriam apenas um modo de dar vazão aos demais campos. Elas não funcionariam apenas como canal amplificador dos processos sociais; e sim, as lógicas midiáticas ressignificariam esses processos.

Com base na perspectiva teórica apresentada, descreveremos e analisaremos a circulação das informações sobre o forró eletrônico na capital cearense, sob a ótica dos conceitos de "esforço produtivo" e "sistema de resposta social", definidos por Braga $(2006 ; 2012)$ como fenômenos que integram o processo de midiatização.

\section{Circulação das Informações sobre o Forró Eletrônico e Fluxo Comunica- cional na Capital Cearense}


Antes de adentrar no processo de circulação das informações em si, apresentamos alguns dados sobre a estrutura da indústria do forró eletrônico em Fortaleza, para compreender de que modo essas empresas pensam a circulação de seus produtos pela cidade. No âmbito dessa cidade, há três grandes empresas de forró eletrônico: a Somzoom ${ }^{6}$ (desde 1991), a A3 Entretenimento $^{7}$ (desde 2006) e a Social Music ${ }^{8}$ (desde 2011). Para sobreviver à força desses três grupos econômicos, os demais precisam firmar parcerias ora com um, ora com outro. Além dessas três grandes indústrias fonográficas, é possível incluir como um grupo em ascensão a F5, que inclui quatro bandas: "Garota Safada" (segunda maior banda do Ceará, após o Aviões do Forró), "Tiaguinho e Mala Mansa", "Forró da Curtição" e "Amor Real”. O vocalista da "Garota Safada", Wesley Safadão, é o principal dono do grupo.

Todas essas empresas adotaram estratégias mercadológicas semelhantes: criar uma estrutura que oferece sustentação às suas bandas. Assim, foram criadas redes de rádio, parcerias com emissoras de televisão, estúdios de gravação, editoras, além de clubes de forró espalhados por Fortaleza e Região Metropolitana.

A Somzoom, por exemplo, surge para dar sustentação de mercado à primeira banda de forró eletrônico, a "Mastruz com Leite", criada em 1990. "Na época, a gente não era muito aceito nas rádios de Fortaleza, então a gente divulgava na rádio da Somzoom". 9 Assim como a Somzoom, a A3 Entretenimento surge somente após a criação de seu primeiro produto, a banda "Aviões do Forró", com o objetivo de fortalecer o grupo e fazer circular esse produto pela cidade. ${ }^{10}$

Além das emissoras de rádio e televisão, as bandas e casas de forró se utilizam, de sites oficiais e redes sociais virtuais (como o Facebook) para divulgar shows, lançamentos, atualizar os fãs sobre as atividades das bandas, realizar promoções e oferecer o serviço de listas de festas, através das quais o público dos clubes pode obter descontos na aquisição dos ingressos.

Apesar de adotarem estratégias de marketing semelhantes, é possível identificar algumas especificidades quanto aos produtos ofertados e aos públicos consumidores. As bandas da Somzoom, por exemplo, não concorrem diretamen- 
te com os grupos mais recentes, da A3 Entretenimento e Social Music, pois atendem a uma demanda pelas "memórias do forró". ${ }^{11}$ Por sua vez, o público dessas duas últimas empresas é considerado mais "sofisticado" e "moderno", o que se aproximaria, em tese, do público que vive na capital cearense. ${ }^{12}$ Assim, na medida em que a A3 ganhou espaço no mercado musical fortalezense, a Somzoom passou a centrar esforços em direção ao interior do Ceará. ${ }^{13}$

Essa estratégia aponta para uma adequação da indústria ao público: na medida em que o contexto social da capital cearense foi seguindo as lógicas de metropolização das cidades, as empresas que não se adaptaram às mudanças comportamentais mais comuns ao espaço urbano tiveram de centrar esforços em outros mercados, como foi o caso da Somzoom.

A partir da perspectiva analítica sobre a midiatização apresentada, analisaremos como ocorre a circulação das informações sobre o forró eletrônico, responsável pela alimentação do "fluxo comunicacional", considerando os dois tipos de circulação do produto midiático, apresentados por Braga (2006; 2012): o "esforço produtivo" e o "sistema de resposta social", ambos responsáveis pelo engendramento do processo de midiatização. O primeiro trata do esforço que a indústria do forró eletrônico realiza para fazer circular suas músicas, bandas e shows por Fortaleza. O segundo trata das respostas dadas pelos consumidores desse produto.

Braga (2012) define o "esforço produtivo" das indústrias culturais como "escuta prevista ou pretendida". Essa escuta não necessariamente corresponde ao modo como os sujeitos irão receber esses produtos, que passam por "fluxo contínuo". "[...] o exercício de diferentes ações, as assimetrias e opressões, devem ser relacionadas antes a cada tipo específico de interação, assim como a seus contextos significativos; e não a uma pretendida lógica diferencial no interagir." (BRAGA, 2012, p. 9).

As indústrias do forró tradicional e do forró eletrônico local divulgam Fortaleza como a "capital do forró". A circulação desta informação auxilia na construção acerca do imaginário sobre a cidade. A propagação deste imaginário ajuda na expansão da indústria fonográfica, que introduz elementos industriais e das vivências urbanas em seus produtos, através de representações sobre o que é 
ser "moderno" e "cosmopolita", ${ }^{14}$ porém fazendo frequentes alusões a um suposto regionalismo que esse gênero musical afirma trazer consigo historicamente, como por exemplo, a utilização da sanfona.

As informações que circulam massivamente pela cidade acerca dos produtos da indústria do forró (músicas, bandas, shows, etc.) é resultado do uso de estratégias de divulgação das indústrias. Assim, o forró eletrônico passa de um subgênero da cultura local, restrito ao consumo das classes subalternas de Fortaleza, para o status de "mainstream local", ${ }^{15}$ resultado das transformações estéticas e gerenciais pelas quais passou (TROTTA; MONTEIRO, 2008, p. 8). O processo de massificação, aliado às novas performances impostas pela cultura e pelo mercado global, exigiu que as bandas adotassem estratégias "arrojadas" no modo de produzir as canções, incluindo novos instrumentos, arranjos, temáticas musicais, e, também, no modo de fazer os shows, as festas com novas coreografias, figurinos que incidiram nas aparências físicas de cantores e dançarinos, dando, assim, ares de "sofisticação".

Nesse cenário, surgem as casas de forró de Fortaleza e Região Metropolitana, principais espaços da sociabilidade dos forrozeiros, lugares onde se divulgam e se consomem as músicas de forró, bens simbólicos transformados em mercadorias. Diante de um conglomerado que envolve emissoras de rádio, sites, gravadoras, editoras, revistas, bandas e casas de shows, além das relações econômicas com televisões locais, alguns dos empresários da indústria do forró eletrônico, ao se referirem aos investimentos que fazem, são taxativos: "Nosso produto mais lucrativo é a festa". ${ }^{16}$ Responsáveis por um lucro menor, os demais produtos dessa indústria (à exceção das bandas, que recebem cachês relativamente altos) são considerados secundários e utilizados estrategicamente para estimular nos consumidores o hábito de frequentar as casas de forró. Desse modo, esses espaços realizam a mediação entre os sentidos que perpassam a circulação das informações e as suas apropriações sobre forró eletrônico, articulada e orquestrada pela complexa malha da indústria cultural.

Com relação às rádios comerciais de Fortaleza, a maioria delas possui programas voltados especificamente para o forró eletrônico. É o caso da Rádio Liderança, da FM 93, da Jangadeiro FM e da Rádio 100. Outras são especializa- 
das em forró eletrônico, como a 102 FM, emissora da A3 Entretenimento, e da Rádio Tropical (FM 92,9). Já na televisão, as bandas de forró ganham visibilidade através de programas como o "Levanta Poeira", "Roça 'N' Roll," "Sábado Alegre", "João Inácio Show", "Forrobodó" e "Nordeste Caboclo", todos da TV Diário, ${ }^{17}$ emissora local do mesmo grupo da TV Verdes Mares, que, por sua vez, é filiada à Rede Globo.

É preciso ressaltar aqui a importância dos gravadores de $\mathrm{CDs}^{18}$ de festas para o processo de circulação desse produto em Fortaleza. No Nordeste e, principalmente, no Ceará, grupos forrozeiros produzem gravações a partir dos shows feitos durante a semana. ${ }^{19}$ São pequenas gravadoras locais e a própria pirataria de CDs que possibilita uma rápida difusão dos repertórios musicais das bandas de forró. Dessa forma, músicas lançadas no sábado, durante shows nas casas de forró, já podem ser ouvidas e baixadas da Internet, no domingo, em forma de $\mathrm{CD}$ e reproduzidas nos mais variados espaços de entretenimento da cidade. As empresas de forró chegam a distribuir esses CDs de modo gratuito, como "CD promocional".

Conforme dito anteriormente, a indústria do forró eletrônico dispõe de um aparato técnico gigantesco, que ajuda a divulgar seus shows e suas bandas através de programas de rádio e televisão, propagandas e divulgação em páginas virtuais que promovem seus produtos. Além disso, os próprios consumidores, ao se apropriarem dos produtos da indústria do forró eletrônico (bandas e shows, principalmente), fazem-nos circular pela cidade. Nesse processo, novas informações são agregadas a esses produtos, criando novos sentidos aos consumidores. É o que Braga (2006) denomina de "sistema de resposta social": um conjunto de ações em que os sujeitos atribuem "sentido social" aos produtos que consomem e fazem circular (BRAGA, 2006). Conforme o autor, essas respostas sociais resultam em uma circulação "diferida e difusa", ou seja, "[...] aquela na qual as informações circulam na sociedade, tornando-se domínio comum (em determinado âmbito) e, nesse nível, podendo chegar ao emissor original ${ }^{20}$ como retorno" (BRAGA, 2006, p. 23).

Pode-se afirmar que, ao criar produtos culturais, a indústria do forró eletrônico cria novos sentidos e propõe usos e apropriações de sentido, mas não os 
consegue impor aos consumidores. Potencialmente, esses consumidores podem reformular esses produtos, apropriando-se de forma singular, atribuindo-lhes novos sentidos no processo de circulação das informações.

Como ponto de partida, consideramos que esses sujeitos chegam aos clubes de forró já cientes de alguns papeis sociais que deverão encenar naquele espaço, papeis esses que podem ser reformulados por cada sujeito. Essas padronizações dos papeis sociais seriam possibilitadas por um processo anterior de circulação de significados no universo do forró, que antecede o momento da festa. Essa circulação ocorre, principalmente, através dos meios de comunicação convencionais, das novas ferramentas midiáticas (a exemplo das redes sociais virtuais), das interações imediatas e de dispositivos tecnológicos utilizados pelos sujeitos sociais em sua vida cotidiana, como os paredões de som.

No processo de circulação das informações, circulam não somente os sentidos presentes em letras das músicas, mas estilos de vida, valores, concepções de mundo etc. A circulação não é um processo meramente técnico instrumental; ela envolve produção das informações e criação de novos sentidos que e se configuram em diferentes formatos: em forma de discursos, de enunciações. "O conceito de enunciação chama atenção para o fato de que o ato discursivo se constitui em um complexo trabalho, uma vez que o sujeito se apropria da linguagem para referir-se, referir o mundo e referir o seu socius. Essa construção evidencia a produção discursiva como uma questão relacional, e não só de caráter transmissional.” (FAUSTO NETO, 2010, p. 8).

Observações participantes e entrevistas realizadas com consumidores de forró eletrônico de Fortaleza apontam para um intenso processo de reformulação dos sentidos propostos pela indústria responsável por difundir esse gênero musical pela cidade. Em suas práticas cotidianas, esses sujeitos demonstram serem agentes de um intenso "sistema de resposta social".

Fundamentamos tal argumento com um caso exemplar: as apropriações do significado das expressões "raparigueiro" e "rapariga" para a sociedade cearense. A expressão "raparigueiro" é, socialmente, considerada "positiva" por fazer alusão aos homens que "saem" com várias mulheres, sem se fixar a nenhuma. Já a expressão "rapariga" é frequentemente utilizada para denominar 
"puta" ou "amante", ou seja, aquelas mulheres que "não servem" ao casamento. Ao contrário do "raparigueiro", "rapariga" é uma expressão ofensiva, um xingamento.

Representado pela indústria do forró como "cabra macho", Zé Cantor, vocalista da banda "Solteirões do Forró", tem interpretado a música "Só papai" 21 em suas apresentações mais recentes, nos clubes de forró da cidade. A música exalta a figura do "raparigueiro", que se esbalda no consumo de bebidas alcoólicas e paga mulheres por sexo. Em tese, seria uma música produzida para o consumo masculino. No entanto, através de observação participante em casas de shows da capital cearense, percebemos que a música mobiliza performances masculinas e femininas de modo bastante semelhante. Ao se apropriarem dessa música, as consumidoras não se colocam no papel de "raparigas" (de caráter negativo), mas de "raparigueiras" (de caráter positivo), adaptando, de modo aparentemente inesperado, as funções sociais que, a priori, aquela música atribui à mulher.

"Mais raparigueira do que eu, só mamãe", gritam muitas das mulheres, na plateia, fazendo uma apropriação "bem-humorada" da composição original, interpretada pelo vocalista da banda. Afirmar-se como "raparigas" não teria o mesmo sentido social que se afirmar como "raparigueira". Embora a ideia das duas expressões seja a de que a mulher em questão se relaciona com diversos homens, a primeira delas atribui um sentido negativo a essa prática, enquanto a segunda faz a exaltação de tal comportamento, o que pode ser lido como tendo um caráter "libertador", pois a trajetória das lutas das mulheres trouxe conquistas importantes que levaram uma atuação política na esfera pública, além de trazer maior autonomia e determinação do seu corpo e de sua sexualidade.

Essa apropriação remete ao contexto de conflito de valores, presentes em centros urbanos como Fortaleza. Nele se manifesta o questionamento dos valores patriarcais enraizados na cultura tradicional, permeado por outros fatos recentes como a ascensão da mulher na vida pública, fenômeno cada vez mais acentuado. Embora seja perceptível que alguns comportamentos cotidianos reforçam os preceitos morais dos padrões da sociedade tradicional, marcada pelo 
forte enraizamento da cultura patriarcal, nos clubes de forró são visíveis algumas pequenas mudanças relacionadas a esses padrões.

Ainda dentro da mesma lógica da apropriação de sentidos por parte dos consumidores, citamos, pontualmente, o discurso de uma consumidora de forró, entrevistada em 2011. Ao interpretar a música "Sou foda", ${ }^{22}$ uma adolescente de 19 anos de idade diz: "É a mulher que é safada [risada], que esculacha o homem na cama". No entanto, a música, cantada por um homem, exalta a figura do "homem pegador", que "esculacha" a mulher na cama. Perguntamos a ela, então, quem esculacha, se é o homem ou a mulher. "Os dois. 'Traição é traição', um trai o outro, não quer nem saber". "[A música diz que] o homem se acha muito macho, mas na hora 'agá', não faz nada [risada]'.

É perceptível, assim, que essa consumidora não se resigna em uma posição de subalternidade, atribuída por essa composição à mulher, galgando uma posição que seria destinada ao homem. Ao colocar esse produto para circular em sua vida cotidiana, essa mulher produzirá os sentidos que ela atribui a essa composição e, portanto, esse produto deixa de ter, exclusivamente, os sentidos enunciados por seus idealizadores e compositores.

O produto "forró eletrônico" não é resultado exclusivo do esforço de uma indústria fonográfica, mas fruto de um fluxo comunicacional que toma como base as informações sobre a cultura local. Elas se expressam através das composições musicais, das diversas práticas sociais diluídas em discursos, gestos e ações ritualizadas no cotidiano das pessoas, no cenário das cidades onde atuam. ${ }^{23}$ Assim, um "produto midiático não é o ponto de partida do fluxo", como aponta Braga (2012, p. 9). Esse produto pode ser analisado como um ponto de chegada, “[...] como consequência de uma série de processos, de expectativas, de interesses e de ações que resultam em sua composição como 'um objeto para circular"”.

O fluxo que compõe o processo comunicativo não parte e, mais ainda, não está centrado na "etapa da produção". Entretanto, o produto "[...] é um momento particularmente auspicioso da circulação - justamente porque, consolidado em sua forma que permanece (e que se multiplica, na sociedade em midiati- 
zação), pode continuar circulando e repercutindo em outros espaços" (BRAGA, 2012, p. 9).

Podemos citar como exemplo do exposto acima o relato de Luciano Kikão, compositor de algumas letras de forró eletrônico. Kikão é de Manaus e, após tornar-se conhecido entre os empresários de forró da capital cearense, passou a comercializar suas músicas com frequência no mercado musical da capital cearense.

Cada letra que Kikão escreve tem por base a identidade sonora e o público de uma banda específica. Ele afirma realizar "pesquisa de campo" nas festas de forró para compor suas letras, que, de modo geral, tratam daquilo que ele considera ser o cotidiano do jovem "forrozeiro", com o qual ele mesmo diz se identificar. A música "Parei o meu carrão" 24 exemplifica o contexto social expresso nas suas composições.

Conforme essa abordagem, os fluxos comunicativos são contínuos e se expressam na sociedade em forma de "circuitos".

Na prática social encontramos, então, sobretudo circuitos. Cada setor ou processo de sociedade participa de circuitos múltiplos. Com a midiatização crescente, os campos sociais, que antes podiam interagir com outros campos segundo processos marcados por suas próprias lógicas e por negociações mais ou menos específicas de fronteiras, são crescentemente atravessados por circuitos diversos (BRAGA, 2012, p. 12). [grifo do autor]

Os campos sociais se articulam através desses circuitos, em processos que se caracterizam fortemente pela experimentação. Na relação com o todo social, os campos sociais se apropriam das tecnologias disponíveis e moldam aos seus objetivos, agregando seus próprios sentidos, suas próprias lógicas, ao sistema interacional.

A partir dessa perspectiva, é possível considerar que o "campo da comunicação", caracterizado aqui pela indústria do forró eletrônico, está intimamente conectado aos demais campos que compõem a sociedade em que circulam informações acerca das músicas, das bandas e dos espetáculos desse gênero musical. Faz-se necessário, portanto, um olhar que não apresente a indústria cultural como detentora de uma centralidade onipotente, mas como um dos "pontos" que compõem um complexo circuito informacional. 


\section{Considerações Finais}

O forró eletrônico, como "produto cultural", não é resultado exclusivo do trabalho de uma indústria fonográfica, mas de um processo sociocultural mais amplo, que, em um fluxo comunicacional, dá sustentação cultural ao "polo da emissão", interfere no modo como músicas, bandas e espetáculos circulam pela cidade e, mais que isso, atribui novos sentidos a esses produtos através de um "sistema de resposta social".

Nesse sentido, os fluxos informacionais, a circulação dos produtos e as práticas dos sujeitos podem remodelar processos que não se limitam à produção de conteúdos midiáticos. A comunicação é, então, pensada de modo mais amplo e complexo, interceptada por diversos grupos sociais e não apenas por aqueles que compõem o campo midiático e da indústria do entretenimento.

A análise apresentada aqui acerca do sistema comunicacional em que a indústria do forró eletrônico se insere reflete sobre a necessidade de pensar os produtos culturais a partir das suas singularidades e dos seus contextos sociais. Reforçamos, assim, o posicionamento epistemológico que concebe os fenômenos de comunicação e da informação não como um processo acabado na esfera do que se foi pensado historicamente como "emissores" de conteúdos midiáticos. Consideramos que os produtos culturais são infinitamente reconfigurados na medida em que circulam e são apropriados pelos sujeitos sociais.

Lançamos, desse modo, um olhar mais amplo sobre o "forró eletrônico", buscando ir além das estratégias mercadológicas adotadas pelas empresas desse ramo e além das análises limitadas aos produtos em si (a exemplo de análises de composições musicais), mais comuns entre as pesquisas já desenvolvidas acerca desse tema. É necessária uma análise que considere a complexidade que envolve a produção, a circulação e a apropriação das informações e da sua relação com os fluxos comunicacionais e os processos advindos da criação dos sentidos que os consumidores passam a agregar aos produtos e suas relações com a hibridez dos contextos culturais. 
Pensar as produções culturais a partir da lógica da midiatização da informação é fundamental analisar as diversas articulações e a complexidade que envolve disputas, tensões, resistências e inovações no campo comunicacional. Neste, potencializa-se uma rede complexa de distintas práticas culturais, políticas, econômicas e sociais, quer seja pela ação dos sujeitos, quer seja dos grupos sociais, pois é através das tradições enraizadas nos modos de vida que se produzem os bens culturais e ao mesmo tempo se realizam as disputas de poder estruturadas e configuradas historicamente.

\section{Referências}

BRAGA, José Luiz. A sociedade enfrenta sua mídia: dispositivos sociais de crítica midiática. São Paulo: Paulus, 2006.

BRAGA, José Luiz. Circuitos versus campos sociais. In: JANOTTI JUNIOR, J.; MATTOS, Maria A.; JACKS, Nilda (Org.). Mediação e Midiatização. Salvador: EDUFBA, 2012. p. 31-52.

BRAGA, Robson da Silva. Eu era feio, agora tenho carro: encenações e práticas de consumo em clubes de forró de Fortaleza. 2015. Tese (Doutorado em Comunicação e Informação) - Programa de Pós-Graduação em Comunicação e Informação, Universidade Federal do Rio Grande do Sul, Porto Alegre, 2015.

FAUSTO NETO, Antônio. A circulação além das bordas. In: Mediatización, sociedad y sentido. Diálogo Brasil - Argentina. Rosário: UNR, 2010. p. 2-17.

FAUSTO NETO, Antônio. Fragmentos de uma analítica da midiatização.

Matrizes, São Paulo, v. 1, n. 2, p. 89-105, abr. 2008.

FAUSTO NETO, Antonio. Midiatização, prática social: prática de sentido. In: ENCONTRO ANUAL DA ASSOCIAÇÃ̃ NACIONAL DOS PROGRAMAS DE PÓS-GRADUAÇÃO EM COMUNICAÇÃO, 15., 2006, Bauru. Anais... Bauru: UNESP, 2006. Disponível em:

<http://www.compos.org.br/data/biblioteca_544.pdf $>$. Acesso em: 19 ago. 2015.

FERREIRA, Jairo; FOLQUENING, Victor. O indivíduo e o ator nas brechas da midiatização: contrabandos em espaços conjuminados. Diálogos de la

Comunicación, [S.1], n. 82, 2012. Disponível em:

$<$ http://dialogosfelafacs.net/wp-content/uploads/2012/07/84-Revista-Dialogos- 
O-individuo-e-o-ator-nas-brechas-da-midiatizacao.pdf>. Acesso em: 19 ago. 2015.

GOMES, Pedro Gilberto. Fenomenologia da midiatização. In: SEMINÁRIO DE EPISTEMOLOGIA E PESQUISA EM COMUNICAÇÃO, 1., 2008, São Leipoldo. Anais... São Leopoldo: UNISINOS, 2008. p. 94-106. Disponível em: <http://www.projeto.unisinos.br/midiaticom/conteudo/artigos/2009/Seminario_s 1_Procad_2009.pdf>. Aceso em: 19 ago. 2015.

GOMES, Pedro Gilberto. Sociedade em midiatização: saudade ou esperança? São Leopoldo: Unisinos, 2010.

JENKINS, Henry. Cultura da convergência. São Paulo: Aleph, 2008.

MARTÍN-BARBERO, Jesús. As formas mestiças da mídia, Pesquisa Fapesp, São Paulo, nº 163, p. 10-15, set. 2009.

MARTÍN-BARBERO, Jesús. Dos meios às mediações. Rio de Janeiro: UFRJ, 1997.

TROTTA, Felipe; MONTEIRO, Márcio. O novo mainstream da música regional: axé, brega, reggae e forró eletrônico no Nordeste. Revista da Associação Nacional dos Programas de Pós-Graduação em Comunicação (E-Compós), Brasília, v. 11, n. 2, maio/ago. 2008.

VERON, Eliséo. Esquema para el análisis de la mediatización. Diálogos, Buenos Aires, n. 48, p. 9-16, 1997.

\title{
The Movement Process of Informations about Electronic Forró and its Flow Communicational in Fortaleza
}

\begin{abstract}
Based on interviews with producers and consumers of electronic forró, this article reflects about the movement process of this musical genre in Fortaleza, Ceará's principal city, sustaining in the concepts of "flux communicational" and "social response system", by José Luiz Braga (2006).This cultural product is not exclusive result of a phonographic industry's work, but of a sociocultural process wider, that, in a flow communicational, gives cultural base to the production, interferes on the way how this product circulates at town and, more than that, attributes new meanings to this product through a "social response system".
\end{abstract}


Keywords: Electronic forró. Information Movement. Mediatization.

Recebido em 21/03/2015

Aceito em 08/10/2015

${ }^{1} \mathrm{O}$ artigo é resultado da tese de doutoramento “Eu era feio, agora tenho carro": encenações $e$ práticas de consumo em clubes de forró de Fortaleza, defendida em 2015, no Programa de Pósgraduação em Comunicação e Informação da Faculdade de Biblioteconomia e Comunicação da UFRGS. A pesquisa sistematizada foi dividida em quatro etapas: 1) pesquisa quantitativa (para definir o perfil sociodemográfico dos dois clubes); 2) observação não participante (para identificar formas simbólicas utilizadas nos clubes); 3) observação participante (para perceber de que modo os consumidores usam as formas simbólicas nas interações); 4) e entrevistas etnográficas (para compreender os sentidos sociais que sustentam tais formas simbólicas, as apropriações que são feitas delas e as encenações do eu através de processos interacionais).

2 O gênero "forró eletrônico" diferencia-se do tradicional "forró pé de serra", tanto em termos de ritmos e letras. Enquanto o primeiro faz alusões a espaços mais urbanos, vivências mais juvenis e tempos mais contemporâneos, o segundo faz alusão aos modos mais tradicionais e rurais de viver da região Nordeste do Brasil. Enquanto o primeiro utiliza instrumentos musicais como bateria, saxofone e guitarra, o segundo se limita ao "trio nordestino" (triângulo, sanfona e zabumba).

${ }^{3}$ Entrevista com artistas cearenses considerados "tradicionalistas", que consideram o forró eletrônico como uma "deturpação da cultura regional".

${ }^{4}$ Em entrevista concedida em 2009, Martín-Barbero propõe ampliar o olhar que lançou sobre o processo comunicativo em seu livro "Dos meios às mediações" (1997). Ele passa, então, de um olhar sobre as "mediações culturais da comunicação" (pensar como a cultura forja práticas comunicacionais) para um olhar sobre as "mediações comunicativas da cultura" (pensar como os processos comunicativos modificam as práticas culturais). Esse seria um dos fundamentos epistemológicos da disciplina de Midiatização, que autores como Fausto Neto e José Braga defendem.

${ }^{5}$ Entrevistas semi-estruturadas e de caráter exploratório. Todas elas seguiram um roteiro preestabelecido, mas permitiram que os entrevistados trouxessem novos elementos, que foram devidamente explorados sempre que se tornava perceptível sua importância para a compreensão da questão trazida por esta pesquisa. As entrevistas foram realizadas em locais escolhidos pelos próprios sujeitos, considerando que eles agiriam de modo mais espontâneo em ambientes onde eles se sentissem mais à vontade.

${ }^{6}$ A Somzoom mantém as bandas "Mastruz com Leite" (a primeira banda de forró eletrônico do Brasil), "Catuaba com Amendoim", "Cavalo de Pau" e "Mirella e Doce Aventura"; a rede Somzoom Sat, produtora de conteúdo que transmite para 18 emissoras de rádio espalhadas pelo Ceará; uma casa de shows na periferia de Fortaleza (Balança Brasil); além de estruturas de festas (para aluguel e uso próprio), gravadora e editora própria.

7 Atualmente, integram o casting da A3 as bandas "Aviões do Forró", "Solteirões do Forró", "Forró do Muído", "Forró dos Plays" e "Boca a Boca"; as casas de shows "G4" (Galpão 4), "Kangalha" e "Estacionamento do Sítio"; e as rádios "A3 FM" (frequência 91,3 MHz) e Rádio 100 FM (Frequência 100 MHz).

${ }^{8}$ Ao romper com a A3 Entretenimento, em 2011, André montou a Social Music, empresa que se vincularia à For Music, com sede em Recife (Pernambuco). Entre propriedades e parcerias, a Social Music participa dos lucros das bandas Forró do Bom, Forró Real, Lagosta Bronzeada e 
Styllo; possui parcerias com as casas de eventos Danadim, The Club, Faroeste, Engarrafamento, Mucuripe Club e Balança Brasil (essa última sendo da Somzoom); e mantém a rádio Liderança (FM 89,9).

${ }^{9}$ Entrevista com um produtor musical da Somzoom. Opto, neste artigo, por não divulgar o nome de alguns dos entrevistados, com o objetivo de preservar suas identidades

${ }^{10}$ Entrevista com Antônio Isaías, em julho de 2011, na sede da A3 Entretenimento, em Fortaleza.

${ }^{11}$ Por ser a empresa mais antiga de forró eletrônico no Ceará, a Somzoom tem se voltado a shows cujo repertório é formado por músicas que fizeram sucesso na década de 1990, através de bandas do grupo, como Forró Mastruz com Leite e Cavalo de Pau.

${ }^{12}$ Análise feita por produtores das empresas citadas, em entrevistas concedidas em 2011.

${ }^{13}$ Exemplo disso é o fato de a rede Somzoom Sat, produtora de conteúdo que transmite para 18 emissoras de rádio espalhadas pelo Ceará, ter cortado a transmissão em Fortaleza. O estúdio da Somzoom Sat está localizado em Fortaleza, onde não há, contudo, veiculação da emissora.

${ }^{14}$ A partir dos anos 2000, a indústria do forró eletrônico de Fortaleza passou a produzir músicas cujas temáticas tratam de personagens urbanos, como o "universitário", o "playboy" e a "patricinha"; shows em formato de grandes espetáculos; e clubes de forró com aspecto mais "sofisticado", nas palavras dos próprios produtores. No entanto, esses elementos que aludem a uma atmosfera "moderna" e "sofisticada" convivem com outros que fazem alusão a um Nordeste "tradicional", a exemplo de símbolos como o "sertão", o "cabra macho", a sanfona, etc.

15 Trotta (2008) considera que o forró eletrônico é "mainstream" por ser um produto hegemônico, o mais difundido massivamente no contexto do Nordeste brasileiro, e, ao mesmo tempo, é "local" por possuir uma limitação geográfica quanto à difusão; ou seja, em outras regiões, essa indústria não possui a mesma força.

${ }^{16}$ Entrevista realizada em 2011 com um empresário do ramo do forró eletrônico, em Fortaleza.

${ }^{17}$ A TV Diário é uma emissora de televisão do grupo Edson Queiroz, o mesmo grupo responsável pela TV Verdes Mares, a filial da Rede Globo no Ceará. A emissora foi inaugurada em julho de 1998 e tem como proposta divulgar a cultura nordestina, em especial a cearense, através de programas populares que se utilizam de uma linguagem coloquial e de elementos culturais regionais. A grade da TV Diário inclui programas jornalísticos, de esportes, policial, de humor e programas de auditório, em que se apresentam bandas de gêneros como axé, pagode, swingueira, romântico, brega e, principalmente, forró eletrônico.

${ }^{18}$ Exemplo são as gravações feitas por "Henrique CDs", "Stenio CDs", "Felipe CDs", "Junior CDs", "Isaias CDs", "Jordany CDs", "Maciel CDs". A maioria possui sites onde o internauta pode encontrar a gravação dos últimos shows.

${ }^{19}$ Os gravadores não são considerados "piratas", uma vez que são autorizados pelos organizadores dos eventos a montarem suas estruturas de gravação nas casas de shows. Há, contudo, irregularidades no que diz respeito aos direitos autorais das músicas que integram o repertório tocado nas festas e reproduzido nos CDs, pois o Escritório Central de Arrecadação e Distribuição (Ecad) consegue cobrar dos organizadores das festas os direitos autorais das músicas, mas dos gravadores de CDs não. Poucas horas após os eventos, essas gravações já estão disponíveis em formato de MP3 nos sites dos gravadores, que lucram sobre as propagandas de empresas, adicionadas em estúdio às músicas cantadas ao vivo. Essas canções ainda são interpeladas por propagandas e "alôs" proferidos pelos vocalistas das bandas, constituindo o chamado "mercado do alô".

${ }^{20}$ Em nota de rodapé, o autor ressalta que, embora se utilize da expressão "emissor original", considera-a simplificadora, uma vez que não há uma "primeira mensagem" no processo comunicacional.

${ }^{21}$ Mais raparigueiro do que eu / Só papai, só papai, só papai (2x) / Papai foi na zoeira / Voltou sem nem um conto / Pois quando o brega é chique / A cerveja é dez conto / Chegou bebo em casa outra vez / Amigo nem te conto / Papai traçou mamãe ainda deu 50 conto ("Só papai", música da banda Solteirões do Forró, interpretada pelo vocalista Zé Cantor). 
${ }^{22}$ Ele canta: "Sou foda / Na cama eu te esculacho / Na sala ou no quarto / No beco ou no carro / Eu sou sinistro / Melhor que seu marido / Esculacho seu amigo / No escuro eu sou um perigo / Avassalador, um cara interessante / Esculacho seu amante / Até o seu ficante / Mas não se esqueça / Que eu sou vagabundo / Depois que a putaria começou a rolar no mundo / Pra te enlouquecer / Pra te enlouquecer / Todas, todas que provaram não conseguem me esquecer / Ô o pente (8x) / Solteirões mandando brasa, dando sequência ao pente" (Sou foda, música originalmente gravado em ritmo de funk pelo grupo Avassaladores e adaptada para o forró eletrônico por bandas como Solteirões do Forró).

${ }^{23}$ Meu pai paga a minha faculdade / Não quero ser doutor / não nasci pra estudar / Sou formado no meio da putaria / No posto de gasolina saio pra farrear / Encontrar a moçada / Tomar uma gelada / eu só ando arrumado / Cheio da mulherada / Sou um playboy arretado / Aqui tá muito bom (bom, bom, bom) / Carro turbinado / Abre a mala e solta o som / Eu gosto é de zoeira / Eu to na putaria / Sou Doido por mulher / E gelada todo dia (Playboy Arretado, música da banda Solteirões do Forró).

24 "Parei o meu carrão lotado de menina / Liguei meu paredão no posto de gasolina... (4x) / Botei um cd que a mulherada gosta / Que swing é esse que essa banda toca? / Quando toca o cd a mulherada encosta / Vou pegar elite de toda a cidade / Pega as patricinhas lá da faculdade / Sou um playboy que a mulherada gosta / Que swing é esse que essa banda toca? / Quando toca o cd a mulherada encosta" (Parei o meu carrão, da banda Furacão do Forró; composição de Luciano Kikão). 